Int. J. Electrochem. Sci., 15 (2020) 4915 - 4930

\title{
Effect of Chloride Ion on Corrosion of Mild Steel in the 7.0 mol/L $\mathrm{H}_{3} \mathrm{PO}_{4}$ Solution in the Presence of 1,10-Phenanthroline
}

\author{
Ji-Tong Gong, Yi-Jing Liu, Lin Wang*, Yan Qin, Yin-long Bai, Dong-Mei Lu \\ School of Chemical Science and Technology, Key Laboratory of Medicinal Chemistry for Nature \\ Resource, Ministry of Education, Yunnan University, Kunming, Yunnan, 650091, P. R. China \\ *E-mail: wanglin@ynu.edu.cn (L. Wang); wanglin2812@163.com
}

doi: $10.20964 / 2020.06 .77$

Received: 4 February 2020 / Accepted: 7 April 2020 / Published: 10 May 2020

\begin{abstract}
The inhibition effects of chloride ion and 1,10-phenanthroline (PTL) on the corrosion of mild steel in $7.0 \mathrm{~mol} / \mathrm{L} \mathrm{H}_{3} \mathrm{PO}_{4}$ solution were studied by potentiodynamic polarization, electrochemical impedance spectroscope and weight loss techniques. The results reveal that $\mathrm{Cl}^{-}$can inhibit the corrosion of mild steel in $7.0 \mathrm{~mol} / \mathrm{L} \mathrm{H}_{3} \mathrm{PO}_{4}$ solution to some extent, while the combination of $\mathrm{Cl}^{-}$and PTL obviously improves the corrosion inhibition and shows better synergistic inhibition effect on mild steel corrosion in $7.0 \mathrm{~mol} / \mathrm{L} \mathrm{H}_{3} \mathrm{PO}_{4}$ solution. The electrochemical studies indicate that $\mathrm{Cl}^{-}$alone or the combination of $\mathrm{Cl}^{-}$and PTL acts as a mixed type of inhibitor for mild steel in $7.0 \mathrm{~mol} / \mathrm{L}$ phosphoric acid and the corrosion reaction is controlled by charge transfer. The adsorption of $\mathrm{Cl}^{-}$on the mild steel surface follows Langmuir adsorption isotherm in the absence or presence of PTL. The kinetic and thermodynamic parameters $\left(E_{\mathrm{a}}, \Delta H_{a}, \Delta S_{a}, K_{\text {ads }}\right.$ and $\left.\Delta G_{\text {ads }}^{\mathrm{o}}\right)$ were calculated and discussed. The adsorption process of the inhibitor molecules on the mild steel surface is spontaneous and contains coexistence of physical and chemical adsorption, while physical adsorption is absolutely dominant.
\end{abstract}

Keywords: Corrosion, 1,10-Phenanthroline, Chloride ion, Mild steel, Phosphoric acid, Synergistic inhibition.

\section{FULL TEXT}

(C) 2020 The Authors. Published by ESG (www.electrochemsci.org). This article is an open access article distributed under the terms and conditions of the Creative Commons Attribution license (http://creativecommons.org/licenses/by/4.0/). 